\title{
DISCAPACIDAD PSÍQUICA “MENOR”, MEDIDAS DISCIPLINARIAS EN EL MARCO DE UNA RELACIÓN DE EMPLEO, DISCRIMINACIÓN Y AJUSTES. COMENTARIO A LA SENTENCIA DEL TRIBUNAL CONSTITUCIONAL DE 15 DE MARZO DE 2021 (STC 51/2021)
}

\author{
Ricardo Esteban Legarreta \\ Profesor titular de Derecho del Trabajo y de la Seguridad Social. Universitat Autònoma \\ de Barcelona.
}

\begin{abstract}
Resumen. El comentario tiene por objeto el análisis de una sentencia del Tribunal Constitucional ante una sanción disciplinaria impuesta a un empleado público con un grado leve de deficiencia psíquica. El comentario se centra, en primer lugar, en la protección dispensada por el Tribunal Constitucional ante una discapacidad que no alcanza los umbrales exigidos por la Ley. Asimismo, el artículo se detiene en el deber de proveer de adaptaciones laborales, que podrá exigirse incluso en caso de ocultación de discapacidad y, en fin, aborda la vulneración del derecho a la presunción de inocencia y la necesidad de culpabilidad para sancionar.
\end{abstract}

Summary. This commentary deals with a constitutional judgement on a disciplinary punishment imposed to a public employee with a minor mental impairment. First, the paper focuses on the protection against discrimination in case of minor disabilities which are outside the legal threshold of disability. Besides, the paper also deals with the duty to provide reasonable adjustments, even when the disabled employee hides his or her impairment. Finally, the commentary focuses on the violation of the right of presumption of innocence and the principle of guilt.

Title: "Minor" mental disability, disciplinary measures in the context of a employment relationship, discrimination and adjustments. Commentary on the Constitutional Court judgment of 15th march 2021 (STC 51/2021).

Palabras clave: discapacidad, discriminación, ajustes, sanción disciplinaria, Key words: disability, discrimination, adjustments, disciplinary punishment.

IUSLabor 1/2021, ISSN 1699-2938, p. 316-330

DOI. 10.31009/IUSLabor.2021.i02.11

Fecha envío: 15.5.2021 | Fecha aceptación: 27.5.2021 


\section{Sumario}

1. Referencia a los antecedentes de la resolución

2. La consideración de la discapacidad por debajo de un porcentaje del 33 por 100 del baremo. Un precedente de gran relevancia

3. El deber de provisión de ajustes por parte de las entidades empleadoras y el carácter discriminatorio de su incumplimiento

3.1. Consideraciones generales de la STC de 15 de marzo de 2021

3.2. Implementación de adaptaciones, ¿también en caso de ocultación de la discapacidad?

4. La vulneración de la presunción de inocencia (24.2) y del principio de culpabilidad (25 CE)

5. Algunas consideraciones sobre el impacto de la sentencia

6. Bibliografía 


\section{Referencia a los antecedentes de la resolución}

La sentencia de la Sala Primera del Tribunal Constitucional de 15 de marzo de 2021 STC 51/2021 - aborda diversas cuestiones en la resolución de un recurso de amparo presentado por un funcionario de la Administración de Justicia, afectado de síndrome de Asperger contra la sanción impuesta por el Ministerio de Justicia por el incumplimiento de algunas de sus obligaciones. En particular, el empleado público, que desempeñaba funciones de Secretario Judicial en un Juzgado de la Comunidad Autónoma de La Rioja había cometido errores y aparente negligencia en el cumplimiento de algunas de sus obligaciones profesionales detalladas en un informe de junio de 2015 en el que se señalaban "deficiencias en la llevanza informática de la cuenta de consignaciones del Juzgado y del sistema integrado de Registros administrativos al servicio de la administración de Justicia"1.

En un primer momento de las actuaciones, en el año 2013, al observarse "que no parecía tratarse de un caso de indisciplina, sino de falta de preparación suficiente o de competencia, actitud y aptitud como secretario judicial", el Ministerio de Justicia había optado por intentar que el funcionario abandonase el servicio por la vía de una jubilación por incapacidad. Sin embargo, el Equipo de Valoración de Incapacidades de la Dirección Provincial del INSS de La Rioja no apreció la concurrencia de dicha circunstancia ya que el funcionario no estaba "afectado por lesión o proceso patológico, estabilizado e irreversible o de incierta reversibilidad, que le imposibilite totalmente para las funciones que desempeña en su puesto de trabajo".

Y precisamente, es en el momento de recibir el pliego de cargos --septiembre de 2015-que el funcionario revela a la Administración de Justicia su condición de persona afectada de síndrome de Asperger, alegando que no había informado de la situación porque entendía que la cuestión pertenecía al ámbito de su intimidad. Para ello aporta el informe del psiquiatra que le había tratado hasta ese momento desde 2002 y propone una diligencia de reconocimiento psiquiátrico, solicitud que no es aceptada. Asimismo, advierte de su derecho a ajustes razonables en su puesto de trabajo, de modo que sin

\footnotetext{
${ }^{1}$ Los incumplimientos imputados muestran especial relevancia ya que se reprocha al funcionario que " $A$. Desconoce la necesidad de visionar los juicios mientras se celebran [..]; B. Reiterada negligencia y retraso injustificado en el cumplimiento de la función de velar por la exactitud de la información transmitida a los Registros Centrales que conforman el sistema Integrado de Registros al Servicio de la Administración de Justicia [...] C. Reiterada negligencia y retraso injustificado en el cumplimiento de la función de responder por el debido depósito de las cantidades, valores, consignaciones y fianzas, siguiendo instrucciones que al efecto se dicten [...] D. Incumplimiento de forma reiterada de la obligación de organización, gestión, inspección y dirección del personal en aspectos técnicos procesales y dirección técnico procesal de personal integrante de su oficina Judicial [...]”.
} 
mediar ajustes la sanción incurriría en discriminación por causa de discapacidad, circunstancia que no fue atendida.

En lo que concierne a la presencia de la discapacidad, los antecedentes del caso muestran que en la fase de escrito de descargos el recurrente no había pasado por un proceso de evaluación de la misma, en base a lo previsto en el RD 1971/1999, de 23 de diciembre, pero sí obtuvo el 10 de febrero de 2016 una primera resolución del Gobierno de la Rioja en la que se le reconocía un grado de discapacidad del 10 por 100, apreciándose un "trastorno de desarrollo de etiología no filiada", pero sin alcanzar en este momento ${ }^{2}$ el grado del 33 por 100 de discapacidad exigido por el artículo 4.2 de la Ley General de Derechos de las Personas con Discapacidad aprobado mediante el Real Decreto Legislativo 1/2013 (en adelante LGDPD). Esta circunstancia fue alegada por el recurrente ante la propuesta de sanción, insistiendo en su derecho a la adopción de medidas de ajuste razonable, pero el procedimiento sancionador siguió adelante y se le acabó imponiendo una contundente sanción consistente en la suspensión de empleo y sueldo de un año y un día, mediante resolución de la Secretaría de Estado de Justicia de 8 de junio de 2016.

La posterior impugnación judicial de la sanción, a través del procedimiento especial de tutela de los derechos fundamentales, ante el Juzgado de lo Contencioso primero y ante la Sala de lo Contencioso-Administrativo de la Audiencia Nacional en un momento posterior no obtuvo los resultados esperados en lo referente a la tutela de su derecho a la no discriminación (artículo $14 \mathrm{CE}$ ), vulneración de la integridad moral (artículo $15 \mathrm{CE}$ ), a mantenerse sin perturbaciones ilegítimas en el desempeño de sus funciones como letrado de la Administración de Justicia (artículo 23.2 CE), pero sí un reconocimiento en modos diversos-de la vulneración del derecho a la presunción de inocencia en base a unas llamativas irregularidades cometidas en el procedimiento disciplinario -cuatro testigos anónimos y un testigo "sorpresa" - que vulnerarían el derecho del funcionario a un procedimiento con todas las garantías. De todos modos, la tibieza con la que esta cuestión fue abordada por la jurisdicción contencioso-administrativa-especialmente por la Audiencia Nacional ${ }^{3}$ - fue corregida con contundencia por el Tribunal Constitucional.

El Tribunal Constitucional declara finalmente que se ha producido una vulneración del derecho a la igualdad de trato y no discriminación por razón de discapacidad (artículo 14

\footnotetext{
${ }^{2}$ La STC refiere cómo mediante resolución de 18 de octubre de 2018, tiempo después de la imposición de la sanción, quedó resuelto el procedimiento de revisión del grado de discapacidad, que le reconoció un porcentaje del 34 por 100 .

${ }^{3} \mathrm{Al}$ respecto, la Audiencia Nacional no declaró vulneración de derechos fundamentales en el procedimiento porque la sanción impuesta podía mantenerse con la sola prueba documental de cargo que existía, siendo la testifical anónima meramente corroboradora de esta, por lo que no procede anular las actuaciones y retrotraer el expediente sino simplemente prescindir de esa prueba confirmando la resolución.
} 
de la Constitución Española, en adelante CE) y, además, que se han vulnerado en el procedimiento sancionador el derecho a un proceso con todas las garantías y a la presunción de inocencia (artículo 24.2 CE) y el principio de culpabilidad (artículo 25 de la CE).

A los efectos de vertebrar el comentario que sigue, se han seleccionado una serie de cuestiones de especial relevancia. De un lado, el pronunciamiento del tribunal impacta en el 1) concepto o noción de persona con discapacidad con una perspectiva ampliatoria que merece una especial atención. A ello cabe añadir la importancia de la resolución a la hora de subrayar 2) el deber de introducir ajustes o adaptaciones en un marco insuficientemente regulado, con independencia de que conste o no la discapacidad del empleado. Finalmente, 3) se efectúan algunas consideraciones a propósito de la vulneración de la presunción de inocencia y del principio de culpabilidad.

Con carácter general, el comentario trata de combinar una mirada general en perspectiva de empleo, teniendo en consideración algunos elementos del empleo en la empresa privada, sin perjuicio de la que la sentencia se dicta en el marco de un vínculo funcionarial.

\section{La consideración de la discapacidad por debajo de un porcentaje del 33 por 100 del baremo. Un precedente de gran relevancia}

La sentencia aborda un interesante debate entre la preeminencia del concepto social de discapacidad (artículo 4.1 LGDPD) y el concepto médico (artículo 4.2 LGDPD). A este respecto, el empleado público había alegado ante el Ministerio de Justicia la resolución de la Comunidad Autónoma de la Rioja en la que se apreciaba un 10 por 100 de discapacidad, sin que el Ministerio apreciase la concurrencia de la discapacidad. Por su parte, el Tribunal Constitucional hace suyas las alegaciones efectuadas por el funcionario recurrente en el sentido de defender una noción social de persona con discapacidad no condicionada a haber alcanzado un grado del 33 por 100, que sería el aparentemente exigido por el artículo 4.2 LGDPD. En este sentido, el criterio adoptado por el Tribunal Constitucional se basaría en argumentos de notable interés.

Por una parte, el Tribunal Constitucional da por buena la noción social de discapacidad reflejada en el artículo 4.1 de la LGDPD que, como es sabido, define la discapacidad sin referencia a grado de deficiencia alguno, apuntando que son personas con discapacidad "aquellas que presentan deficiencias físicas, mentales, intelectuales o sensoriales, previsiblemente permanentes que, al interactuar con diversas barreras, puedan impedir su participación plena y efectiva en la sociedad, en igualdad de condiciones con las demás". Por lo tanto, como alega la parte recurrente no se excluye del ámbito de 
aplicación de dicha Ley a las personas que puedan, en base a la definición del artículo 4.1 LGDPD, ser "personas con discapacidad, aunque carezcan de reconocimiento administrativo de su grado de discapacidad o lo tengan reconocido en un porcentaje menor". Ahora bien, no debe olvidarse que nuestra legislación abre la puerta a un planteamiento más restrictivo ya la LGDPD establece en su artículo 4.2 que "Además de lo establecido en el apartado anterior, y a todos los efectos, tendrán la consideración de personas con discapacidad aquellas a quienes se les haya reconocido un grado de discapacidad igual o superior al 33 por ciento" .En este sentido, podría concluirse que solo son personas con discapacidad las que cumplan con el requisito general del artículo 4.1 pasado por el tamiz del artículo 4.2 de la Ley, es decir, siempre que se acredite un grado de discapacidad del 33 por 100 tras alcanzar o superar ese umbral en el marco del procedimiento de evaluación regulado por el RD 1971/1999.

El Tribunal Constitucional esquiva esta lectura rígida en el caso concreto, lo que dicho sea de paso encuentra claros apoyos interpretativos, El primero, una interpretación de nuestra Ley alineada con la Convención de los Derechos de las Personas con discapacidad en cuyo texto la noción de persona con discapacidad está desprovista de toda referencia a porcentajes o baremos, porque la Convención profundiza de un modo muy significativo en la noción social de discapacidad. No en vano, el artículo 1 párrafo segundo de la Convención señala que son personas con discapacidad "aquellas que tengan deficiencias físicas, mentales, intelectuales o sensoriales a largo plazo que, al interactuar con diversas barreras, puedan impedir su participación plena y efectiva en la sociedad, en igualdad de condiciones con las demás". De este modo, si la noción de discapacidad del texto internacional es válida y suficiente, ello refuerza el carácter autónomo del artículo 4.1 de la LGDPD. Abundando en esa perspectiva, no hemos de olvidar que la misma LGDPD parece dar carta de naturaleza a la noción social de su artículo 4.1, teniendo en cuenta que el artículo 4.2 define el concepto médico como algo propuesto de manera adicional; a saber, "Además de lo establecido en el apartado anterior" en expresión literal de la Ley, de modo que no sería imprescindible alcanzar los umbrales del artículo 4.2 para obtener la consideración de persona con discapacidad, al menos a a algunos efectos. Por lo demás, debe tenerse en cuenta que ese es también el concepto europeo de persona con discapacidad ya que desde que se produjo la ratificación de la Convención Internacional de los Derechos de las Personas con Discapacidad por parte del Consejo de la Unión Europea -Decisión 2010/48/CE de 26 de noviembre-la jurisprudencia europea ha adoptado ese concepto, un criterio abierto en su día por la STJUE de 11 de abril de 2013 (Asuntos Acumulados 335/11 y C 337-11, HK Danmark-Ring).

El planteamiento del Tribunal Constitucional constituye un espaldarazo a otras resoluciones judiciales que se abren paso tímidamente y que están reconociendo situaciones de discriminación laboral "por razón" de discapacidad, aunque no concurra 
en el supuesto una discapacidad evaluada. Este es el caso de la STSJ de Galicia de 13 de abril de 2021 (rec 160/2020) en la que se aprecia la nulidad de un despido llevado a cabo sobre un trabajador accidentado porque del cuadro médico inmediatamente posterior al accidente de trabajo - que es cuando el empleador decide despedir al trabajador sin causa -, cabe deducir una apariencia razonable de discapacidad y por lo tanto, un móvil discriminatorio en la decisión empresarial fundamentada en esta circunstancia. Asimismo, nuestro Tribunal Constitucional se alinea con la jurisprudencia del Tribunal de Justicia de la Unión Europea que tiende a permitir la apreciación de discapacidad en supuestos de limitaciones fisiológicas duraderas, aun cuando no concurra una situación de discapacidad consolidada, como sucede en la STJUE de 1 de diciembre de 2016 (Asunto C-395/15, Daouidi); o en el caso de trabajadores reconocidos como especialmente sensibles, si las circunstancias del caso permiten esta asimilación, como apunta la STJUE de 11 de septiembre de 2019 (Asunto C-397/18, Nobel Plastiques Ibérica). Todo ello podría llevar a la regulación de un concepto de discapacidad más social, a utilizar en el marco de la protección contra la discriminación ${ }^{4}$.

Ciertamente, en el supuesto objeto de este comentario el Ministerio de Justicia podría también haber apreciado esa apariencia o principio de discapacidad lo que, obrando con mayor diligencia le habría llevado a archivar el procedimiento sancionador y a implementar ajustes que permitiesen al funcionario un adecuado cumplimiento de sus funciones.

Por lo demás, cabe señalar que, desde una visión general de la noción de persona con discapacidad de la LGDPD, el planteamiento del Tribunal Constitucional cuestiona de alguna manera la lógica seguida por una jurisprudencia del Tribunal Supremo de notable repercusión -sentencias del 19 de noviembre de 2018 y ulteriores - contraria a la equiparación automática a discapacidad de la incapacidad permanente en los grados de total y absoluta prevista en el inciso final del artículo 4.2 LGDPD. Aunque se trata de sentencias dictadas en un contexto más general, cabe recordar que en base a aparentes razones de constitucionalidad, al menos cinco sentencias del Tribunal Supremo, tres de ellas dictadas el 19 de noviembre de $2018^{5}$, ha considerado inaplicable el inciso final del artículo 4.2 de la LGDPD, de modo que actualmente, y a pesar de la dicción literal de la LGDPD no puede asimilarse a persona con discapacidad a todas aquellas "que tengan

\footnotetext{
${ }^{4} \mathrm{Al}$ respecto, puede verse GUTIÉRREZ COLOMINAS, David.: La obligación de realizar ajustes razonables en el puesto de trabajo para personas con discapacidad: una perspectiva desde el derecho comparado y el derecho español, Albacete, Bomarzo, 2018, p. 197 y ss en la que se plantea en el derecho francés la existencia de más de un concepto de persona con discapacidad.

${ }^{5}$ Se trata de tres sentencias dictadas con los siguientes números de recurso: 3382/2016 (RJ 2018/5846) rec. 1826/2017 (RJ 2018/5942) y rec. 239/2018 (RJ 2018/6053), a las que se han añadido posteriormente la STS de 19 de febrero de 2020 (rec. 2927/2017) y la STS de 12 de mayo de 2020 (rec. 243/2018).
} 
reconocida una pensión de incapacidad permanente en el grado de total, absoluta o gran invalidez, y a los pensionistas de clases pasivas que tengan reconocida una pensión de jubilación o de retiro por incapacidad permanente para el servicio o inutilidad". En realidad el planteamiento del Tribunal Supremo ${ }^{6}$, muy exigente desde el punto de vista médico, vendría a requerir que las personas declaradas en situación de incapacidad permanente superen el procedimiento de calificación del RD 1971/1999 y alcancen siempre y en todo caso el grado de discapacidad del 33 por 100, lo que de alguna manera diverge del planteamiento del Tribunal Constitucional que precisamente ha procedido a relajar la necesidad de alcanzar ese umbral al apreciar una situación de discapacidad "materialmente social" que también podría apreciarse en las personas con incapacidad permenente en grado de total o superior ${ }^{7}$.

\section{El deber de provisión de ajustes por parte de las entidades empleadoras y el carácter discriminatorio de su incumplimiento}

\subsection{Consideraciones generales de la STC de 15 de marzo de 2021}

El Tribunal Constitucional insiste en una cuestión contemplada en nuestra legislación ordinaria y es que, de conformidad con el artículo 63 de la LGDPD, la no provisión de adaptaciones será constitutiva de una discriminación por razón de discapacidad ${ }^{8}$. En este sentido, el Tribunal entiende que no cabe la adopción de despidos, separaciones de servicio o bien sanciones disciplinarias si el empleador no cumple con su obligación de proveer los ajustes, particularmente cuando el empleado solicita su implementación, aunque se trate de una petición efectuada una vez incoado el expediente sancionatorio. En este sentido, señala la sentencia en su fundamento jurídico cuarto que "Cuando una persona solicita en su empleo ajustes razonables por razón de su discapacidad, su petición debe ser objeto de consideración desde el momento en que se solicite y se acredite -conforme a la normativa aplicable — el alcance de la discapacidad", y va de

\footnotetext{
${ }^{6}$ Sobre la cuestión, puede verse: ESTEBAN LEGARRETA, Ricardo, "Algunos aspectos estructurales ante el empleo de las personas con discapacidad", Documentación Laboral, n 120, 2020, págs. 18 a 20.

7 ITURRI GÁRATE, Juan Carlos, “¿No puedo trabajar y no soy persona con discapacidad? Sobre la equiparación de situaciones de incapacidad permanente y el reconocimiento de situación de discapacidad. Comentario a la sentencia del Tribunal Supremo de 1902 2020", Ciudad del Trabajo, nº 32, junio 2020, p. 18.

${ }^{8} \mathrm{~A}$ este respecto cabe señalar que nos encontramos ante una tipología de discriminación por discapacidad específica, diferente a la discriminación directa o indirecta por razón de discapacidad, ya que en el caso de la discriminación por no implementación de ajustes, no se toma como referencia una situación comparable -como sucede en el terreno de la discriminación directa o indirecta - sino que el objetivo de las adaptaciones es "precisamente lograr un trato diferenciado que permita la prestación de servicios en el puesto de trabajo" (GUTIÉRREZ COLOMINAS, David: La obligación de realizar ajustes razonables....ob cit, Albacete, Bomarzo, 2018, p. 258).
} 
suyo que desde un punto de vista procedimental el Tribunal Constitucional no pone reparos aun cuando la solicitud pueda tildarse de "extemporánea" o incluso estratégica, con la pretensión, en el caso objeto de análisis, de paralizar una iniciativa disciplinaria. De no implementarse las adaptaciones, el Tribunal Constitucional recuerda en base al precedente de su sentencia 3/2018, de 22 de enero, que se apreciará resultado discriminatorio que no cabrá justificar en ninguna finalidad legítima, todo ello con independencia de que haya o no una intencionalidad discriminatoria.

El planteamiento del Tribunal Constitucional tiene una especial relevancia porque subraya la existencia de un derecho a adaptaciones laborales que nuestro ordenamiento recoge en el artículo 42 de la LGDPD para el ámbito de la empresa privada y entre otros, en los artículos 59.2 del EBEP y 10 del RD 2271/2004, de 3 de diciembre, de empleo público de personas con discapacidad, para los empleados en la Administración. Y la cuestión es importante porque si bien la materia parece mejor regulada en el ámbito del empleo público, especialmente en materia de adaptaciones en procesos selectivos (artículo 8 RD 2271/2004), su regulación debería mejorarse sustancialmente en el ámbito del empleo privado ya que el artículo 40.2 LGDPD apenas alcanza a reproducir el contenido del artículo 5 de la Directiva 2000/78 CE, del Consejo, de 27 de noviembre de 2000 relativa al establecimiento de un marco general para la igualdad de trato en el empleo y la ocupación, apuntando la norma española a que "Los empresarios están obligados a adoptar las medidas adecuadas para la adaptación del puesto de trabajo y la accesibilidad de la empresa, en función de las necesidades de cada situación concreta, con el fin de permitir a las personas con discapacidad acceder al empleo desempeñar su trabajo, progresar profesionalmente y acceder a la formación, salvo que esas medidas supongan una carga excesiva".

En este sentido, la STC 51/2021 puede suponer un acicate que presione a fin de que se aborde una regulación más detallada que permita definir el alcance de las adaptaciones exigibles, amplíe las exiguas ayudas públicas previstas en el artículo 12 del RD 1451/1983, de 11 de mayo, de empleo selectivo y contribuya a identificar el alcance de la carga excesiva, como supuesto que, en caso de apreciarse, podría eximir a la empresa del cumplimiento del deber de introducir adaptaciones. Al respecto, el último inciso del artículo 40.2 LGDPD apunta a que en la identificación de la carga excesiva "se tendrá en cuenta si es paliada en grado suficiente mediante las medidas, ayudas o subvenciones públicas para personas con discapacidad, así como los costes financieros y de otro tipo que las medidas impliquen y el tamaño y el volumen de negocios total de la organización o empresa". La carga excesiva es una cuestión que plantea menos problemas en el ámbito de las Administraciones públicas de gran dimensión, teniendo en cuenta que el planteamiento del RD 2271/2004 de 3 de diciembre (artículo 10.2) es el de la asunción de las cargas sin mayores matices, al menos por parte de la Administración General del 
Estado mientras que el empleo en la empresa privada deja más margen para la discusión. En el supuesto que motiva el recurso de amparo la cuestión está fuera de toda duda porque no podía alegarse carga excesiva teniendo en cuenta la dimensión de la Administración General del Estado y la relativa simplicidad de las adaptaciones, que probablemente podrían haberse limitado a mejorar la formación ${ }^{9}$ y el acompañamiento del funcionario para facilitarle un adecuado desempeño de sus funciones como Secretario Judicial.

Más allá de la mejora en los elementos substantivos del deber de introducir adaptaciones, el Tribunal Constitucional apunta a otras cuestiones no reguladas expresamente en nuestro ordenamiento, al menos en el ámbito del empleo privado; a saber, la forma en la que deben abordarse las solicitudes de adaptación. El Tribunal Constitucional apunta a que ante una solicitud de adaptaciones, "La respuesta del empleador debe ser expresa y estar debidamente motivada; en particular cuando deniegue los ajustes solicitados por considerarlos desproporcionados o indebidos" (Fundamento jurídico $4^{\circ}$ ). A este respecto, sería positivo que el legislador tome buena nota y regule el procedimiento de solicitud y gestión de las adaptaciones en la empresa privada, como viene a establecer el tercer párrafo de artículo 34.8 TRLET en materia de adaptaciones del tiempo de trabajo y de la forma de la prestación a fin de facilitar la conciliación de la vida laboral y familiar, o como apunta el artículo 10 del RD 2271/2004, en el ámbito de las adaptaciones por discapacidad en la Administración General del Estado. Para ello, se debería repensar el alcance y detalle del vigente artículo 40.2 de la LGDPD para que pueda visibilizarse de un modo más claro el ejercicio de un derecho que hoy por hoy se me antoja marginal ${ }^{10}$. Es más, dicho procedimiento debería tener en cuenta criterios inclusivos de peticiones aparentemente extemporáneas o estratégicas o incluso establecer pautas de comportamiento empresarial en casos de "sospecha de concurrencia de discapacidad", una cuestión abordada en la sentencia y a la que me referiré a continuación. A este respecto, como se verá, la falta de información respecto a la discapacidad no exime al empleador de mantener una actitud proactiva de cara a facilitar las adaptaciones e informar del derecho.

Por lo demás, si estuviésemos en el ámbito de la discriminación indirecta -que no es el caso-, cabría plantearse si la medida disciplinaria implementada podría justificarse objetivamente con una finalidad legítima (artículo 2.1 Directiva 2000/78/CE), que en este

\footnotetext{
${ }^{9} \mathrm{Al}$ respecto, RODRÍGUEZ SANZ DE GALDEANO, Beatriz, "El deber de introducir adaptaciones como medida de acceso y mantenimiento del empleo de las personas con discapacidad", Documentación Laboral, no 120 , 2020, p. 68, señala que "Tendrían cabida como posibles medidas de ajuste la realización de cursos de formación específicos para los trabajadores con discapacidad con el fin de facilitar, entre otras cuestiones, el entendimiento de las funciones del puesto y de los procesos del trabajo".

${ }^{10}$ RODRÍGUEZ SANZ DE GALDEANO, Beatriz, "El deber de introducir adaptaciones...", ob, cit., p.74 se refiere precisamente a la falta de un "cauce especifico en la empresa para proponer la adopción de posibles medidas de ajuste".
} 
caso no podría apreciarse porque carece de sentido emprender medidas disciplinarias cuando no concurre ni intencionalidad incumplidora ni negligencia imputable al trabajador, máxime cuando la sanción implica, ni más ni menos, la suspensión de empleo y sueldo durante un año. En este sentido, la sentencia es también una llamada de atención a los empleadores en la utilización de la vía disciplinaria, ya que deberá ponderarse cuidadosamente su aplicación cuando concurran circunstancias de carácter psicológico que condicionen la continuidad del trabajador en la empresa ${ }^{11}$.

\subsection{Implementación de adaptaciones, ¿también en caso de ocultación de la discapacidad?}

Uno de los elementos más llamativos del caso está en que el empleado público no informó al Ministerio de Justicia del síndrome de Asperger padecido, lo que quedaría amparado por el derecho a la intimidad del empleado público -máxime dado el efecto segregador característico de la enfermedad mental (STC 62/2008, de 26 de mayo)-, y que por lo demás se justificaría por los escasos efectos prácticos que ello comportaba para el funcionario, porque al no disponer de una resolución reconociéndole un 33 por 100 de discapacidad, ello no habría permitido al -en su momento-- aspirante beneficiarse del cupo de reserva en el acceso al empleo público previsto en el artículo 59 del EBEP . El Tribunal Constitucional avala el derecho a mantener discreción sobre la discapacidad/enfermedad y señala que determinadas tipologías de discapacidad van acompañadas de una intensa carga estigmatizante, por lo que es particularmente comprensible su ocultación en primera instancia. En concreto, el Tribunal Constitucional recuerda la vinculación del síndrome de Asperger a la categoría de "Trastornos del Espectro del Autismo", efectuada por la Organización Mundial de la Salud, recordando que "la discriminación que han sufrido secularmente quienes la padecen (la discapacidad psíquica, intelectual o cognitiva) constituyen importantes barreras a la hora de informar de esta forma de discapacidad en el lugar de trabajo". En este sentido, la cuestión cobra una especial relevancia porque nos hallamos ante un espacio de discapacidades que no siempre son perceptibles y que por lo tanto pueden pasar desapercibidas al empleador en el acceso al empleo, lo que se concurre especialmente en el caso de las personas con discapacidad psíquica, que padecen un mayor rechazo social que otros colectivos, los que

\footnotetext{
${ }^{11}$ Cabe apuntar cómo algunas sentencias han admitido la vía de la extinción objetiva por ineptitud ante comportamientos psicológicamente disfuncionales de los que incluso cabría deducir una discapacidad, que en principio no había sido alegada como tal por los trabajadores en sus impugnaciones. Se trata de la STSJ de Andalucía (Sevilla), de 25 de julio de 1995 (rec 865/1995), en la que se aprecia un comportamiento paranoide y la STSJ del País Vasco de 14 de noviembre de 2006 (rec. 2476/2006), en la que se constata que el comportamiento del trabajador deriva de problemas con el alcohol que concurren con una esquizofrenia paranoide en remisión. Se trata de supuestos enjuiciados en un momento en el que no había una formulación contundente del derecho a adaptaciones. Hoy en día cabría plantear en estos casos la posibilidad de introducir adaptaciones antes de proceder a la extinción por causas objetivas.
} 
se traduce en muy bajas tasas de actividad ${ }^{12}$, muy condicionadas por una baja estimación de sus posibilidades en el mercado de trabajo.

Ciertamente, en el terreno del empleo público ocultar la discapacidad comporta que el aspirante no podrá beneficiarse de algunas de las medidas que facilitan el acceso, pero será su opción personal en el bien entendido que las personas con discapacidad no tienen la obligación de optar a las plazas reservadas, sino que tendrán que solicitarlo (artículo 2.1 RD 2271/2004, de 3 de diciembre). Ahora bien, en el caso del acceso al empleo privado puede ser todavía más razonable la ocultación teniendo en cuenta que salvo que el acceso al empleo se lleve a cabo en el marco de una oferta dirigida al cumplimiento de la cuota de reserva de empleo del artículo 42 de la LGDPD -y aun así13 - el efecto estigmatizante que todavía planea sobre determinadas tipologías de discapacidad aconsejaría guardar discreción aunque eso sea disfuncional en un momento posterior, cuando precisamente pueden aparecer necesidades de adaptaciones.

El Tribunal Constitucional añade que será necesaria una particular diligencia por parte de la Administración -o del empleador privado, en su caso-, para detectar necesidades de apoyos, aunque la discapacidad no se explicite. En el caso concreto, si el Ministerio de Justicia impulsó un procedimiento de jubilación por discapacidad, cabía deducir que sospechaba de la discapacidad y de la necesidad adaptaciones o ajustes, y por lo tanto debería de haberlos ofrecido porque al no hacerlo incurrió en una conducta discriminatoria, que posteriormente se vio ratificada manteniendo una conducta pasiva cuando el funcionario solicitó los ajustes.

Para argumentar este deber de prudencia y diligencia a la hora de ofrecer ajustes, el Tribunal Constitucional aporta la Observacion General núm. 6/2018 sobre la igualdad y la no discriminación del Comité sobre los Derechos de las Personas con discapacidad de la Convención de la ONU (párrafo 24, apartado final) en el que se recuerda que "[...] la

\footnotetext{
${ }^{12}$ Los datos avalan el planteamiento del Tribunal Constitucional ya que, según cifras del Instituto Nacional de Estadística, en el año 2019, las personas con enfermedad mental tenían una tasa de actividad del 27’8 por 100, tasa claramente más baja que la media general entre el colectivo de personas con discapacidad 34 por 100--, y muy alejada de tasas de actividad de otros colectivos como es el caso de las personas con discapacidad visual, con una tasa de actividad del 45 por 100. Datos extraídos de INE: El empleo de las personas con discapacidad (2019), Notas de prensa, 2020 Consultable en https://www.ine.es/prensa/epd_2019.pdf

${ }^{13}$ Dado que a la oferta de empleo pueden concurrir personas con diversas tipologías de discapacidad no resulta aventurado pensar en que las personas con discapacidad psíquica pueden padecer un especial rechazo en el marco de un proceso de estas características. Aunque también es verdad que la ocultación no va a ser siempre fácil considerando que muchas personas con discapacidad psíquica van a tener que integrarse en la empresa de una forma planificada, en el marco de procesos de empleo con apoyo, bajo el esquema del RD 870/2007, de 2 de julio.
} 
obligación de proporcionar ajustes razonables no se limita a situaciones en que una persona con discapacidad haya pedido un ajuste o en que se pueda demostrar que el garante de los derechos en cuestión era consciente de que esa persona tenía una discapacidad. También se aplica cuando el posible garante de los derechos debería haberse dado cuenta de que la persona en cuestión tenía una discapacidad que tal vez obligara a realizar ajustes para que esta pudiera superar obstáculos al ejercicio de sus derechos", planteamiento que es compartido por el dictamen de la Abogada General en el procedimiento de la STJUE de 18 de enero de 2018 (Asunto C-270/16 Ruiz Conejero) y que es tenido en cuenta por la SJS de Cuenca de 7 de marzo de 2018 ( $\mathrm{n}^{\mathrm{o}}$ 171/2018) y por la STSJ de Castilla-La Mancha, de 10 de abril de 2019 (rec. 669/2018).

\section{La vulneración de la presunción de inocencia (24.2) y del principio de culpabilidad (25 CE)}

En último término cabe señalar que la sentencia del Tribunal Constitucional declara que se ha producido la vulneración del principio de culpabilidad $(25 \mathrm{CE})$ y el derecho a presunción de inocencia (artículo 24.2 CE) del funcionario (FJ $5^{\circ}$ ). A este respecto, la vulneración del principio de culpabilidad derivaría de la necesidad de apreciar conducta intencionada o negligente del sujeto infractor, y sería de aplicación en el ámbito penal y administrativo sancionador lo que, a juicio del Tribunal Constitucional incluiría a los expedientes disciplinarios de los funcionarios públicos en el ejercicio de sus funciones. Apreciada la vulneración del principio de culpabilidad, el Tribunal Constitucional vincula también la vulneración del derecho a la presunción de inocencia por sus estrechos vínculos con el principio de culpabilidad, ya que "Como regla, se configura como un derecho a no sufrir una sanción a menos que la culpabilidad haya quedado establecida más allá de toda duda razonable". En este sentido, el planteamiento del Tribunal Constitucional es más que razonable si tenemos en cuenta las dudas que suscita la actuación de la Administración, no solo porque inicialmente intentó la vía de la jubilación por incapacidad -muestra evidente de que no estaba convencida de la culpabilidad del funcionario- sino por las graves irregularidades en las que se incurrió en el procedimiento sancionador mediante la presencia de testigos anónimos.

Ciertamente, no es posible extrapolar esas consecuencias de constitucionalidad si la situación planteada se hubiese producido en el marco de un contrato de trabajo, teniendo en cuenta que las garantías constitucionales de los artículos 24.2 y 25 de nuestra Carta Magna no se no se extienden al ámbito disciplinario laboral, ya que su terreno sería el proceso penal y el procedimiento administrativo sancionador ${ }^{14}$.

\footnotetext{
${ }^{14}$ POQUET CATAlà, Raquel, La actual configuración del poder disciplinario empresarial, Valencia, Tirant lo Blanch, 2011, p. 79, con cita y comentario de la STC 153/2000.
} 
Ahora bien, en estricta perspectiva de legalidad si la imposición de la sanción se hubiese producido en el marco de un contrato de trabajo, la falta de intencionalidad y/o de negligencia en el proceder del empleado (artículo 54 TRLET) conduciría, al menos, a la improcedencia del despido disciplinario, por ausencia del requisito de culpabilidad, como se plantea, entre otras, en la STSJ de Castilla-la Mancha de 3 de marzo de 2016 (rec. 1879/2015) en la que concurre un supuesto grave de ludopatía en situación de tratamiento.

\section{Algunas consideraciones sobre el impacto de la sentencia}

La STC 51/2021 constituye un importante paso del Tribunal Constitucional en favor del derecho de las personas con discapacidad a la no discriminación. La sentencia permite visibilizar el derecho a adaptaciones laborales -hoy en día de ejercicio residual—y puede contribuir a impulsar una regulación más detallada de la figura tanto en perspectiva material como desde un punto de vista procedimental. Asimismo, la STC de 15 de marzo de 2021 remarca el carácter discriminatorio de la no provisión de adaptaciones e insiste en la exigencia una actitud proactiva del empleador, incluso ante el silencio del empleado, como ya habían señalado otras sentencias.

Por otra parte, el Tribunal Constitucional opta por sugerir la autonomía del concepto social de discapacidad, reflejado en el artículo 4.1 LGDPD, y desvinculado de un específico porcentaje de discapacidad. Todo ello debería llevar a la reflexión a propósito de si debe repensarse el concepto de persona con discapacidad, al menos en el terreno de la protección antidiscriminatoria, para llevar a cabo una protección más eficaz. En fin, la sentencia constituye una llamada de atención a una mayor sensibilidad hacia las personas con discapacidad psíquica, que sufren de una especial carga discriminatoria.

\section{Bibliografía}

Esteban Legarreta, Ricardo, Algunos aspectos estructurales ante el empleo de las personas con discapacidad", Documentación Laboral, n 120, 2020, p. 11-26.

GUTIÉRREZ COLOMINAS, David: La obligación de realizar ajustes razonables en el puesto de trabajo para personas con discapacidad: una perspectiva desde el derecho comparado y el derecho español, Albacete, Bomarzo 2018.

INE: El empleo de las personas con discapacidad (2019), Notas de prensa, 2020 Consultable en https://www.ine.es/prensa/epd_2019.pdf

ITURRI GÁRATE, Juan Carlos, “¿No puedo trabajar y no soy persona con discapacidad? Sobre la equiparación de situaciones de incapacidad permanente y el reconocimiento de 
situación de discapacidad. Comentario a la sentencia del Tribunal Supremo de 1902 2020”, Ciudad del Trabajo, no 32, junio 2020, p. 119-131.

POQUeT CATALÀ, Raquel: La actual configuración del poder disciplinario empresarial, Valencia, Tirant lo Blanch, 2011.

RodríGuez SANZ DE GALDEANO, Beatriz, El deber de introducir adaptaciones como medida de acceso y mantenimiento del empleo de las personas con discapacidad", Documentación Laboral, nº 120, 2020, p. 59 a 74. 